\title{
EM CASA ONDE FALTA PÃO, TODOS BRIGAM E NINGUÉM TEM RAZÃO
}

Coluna publicada em 3.4.2018: <https://www.conjur.com.br/2018-abr-03/ contas-vista-casa-onde-falta-pao-todos-brigam-ninguem-razao $>$

A sabedoria evidenciada no provérbio popular que dá o título a esta coluna não poderia ser mais apropriada para descrever o presente momento de nossas finanças públicas, que tem colocado em risco o Direito Financeiro.

Das recentes notícias que se tem observado, a conclusão tende a ser uma só: vivemos uma situação que beira o colapso nas finanças públicas (alguns entes federados já ultrapassaram essa fase e o colapso já se instalou....), ${ }^{1}$ e o verdadeiro desespero ante a iminência de descumprimento do ordenamento jurídico financeiro só incentiva a criatividade na contabilidade pública e a interpretação cada vez mais "elástica" das normas de responsabilidade fiscal.

A economista Mônica de Bolle aponta com precisão que "a chamada boa gestão da equipe econômica foi não estragar mais do que já estava estragado e fazer muitíssimo pouco para melhorar", constatando-se uma clara realidade, qual seja, o grande avanço tem sido parar de piorar. $\mathrm{O}$ que, além de evidentemente ser muito pouco, não ataca as causas do problema, como o descompasso entre as despesas em constante elevação, e sem contrapartida nas receitas. E em nenhum momento vê-se destaque a medidas que procuram melhorar a qualidade do gasto público, de modo a melhor aproveitar os recursos já disponíveis. ${ }^{2}$

1 "A situação de boa parte dos estados brasileiros beira o caos", escreveu recentemente Raul Veloso ("Como tirar os estados do buraco". Correio Braziliense, 6 de março de 2018).

2 "Falta de ajuste deteriora dívidas de União, estados e municípios". Folha de S.Paulo, 29 de março de 2018. 
Há poucas semanas, ante o aparente fracasso na tentativa de aprovar em curto prazo a reforma da Previdência Social, ${ }^{3}$ divulgou-se a "agenda prioritária" do governo, na qual estava a aprovação da Lei de Qualidade Fiscal, que tem entre suas pretensões colaborar para a melhoria do gasto público. ${ }^{4}$ Mas não se constata ter havido qualquer movimentação nesse sentido, deixando sérias dúvidas se há uma real priorização dessa medida.

Falando em reforma da Previdência, essa questão tão relevante continua pouco clara e transparente, e as sérias divergências que envolvem o debate sobre o tema não têm respostas satisfatórias. O governo, após a extinção do Ministério da Previdência Social e a verdadeira "dispersão" dos órgãos e recursos a ele vinculados, em nada colabora para tornar menos obscura a discussão, como abordamos na coluna É preciso ter cautela e transparência para debater a reforma da Previdência. ${ }^{5}$

Vê-se que a dívida pública não para de aumentar, seu crescimento tem quebrado recordes, atingiu $75 \%$ do PIB, ${ }^{6}$ e só não se deteriorou mais por questôes pontuais, como devoluções de recursos do BNDES ao Tesouro, uma vez que as medidas de ajuste estrutural não conseguem ser implementadas.

O reflexo dessa medida vê-se nitidamente nas metas fiscais, que obviamente devem ser sempre positivas, mas já há algum tempo foi “jogada a toalha”. Reconhecida a incapacidade de manter as contas públicas em ordem, têm sido fixadas metas fiscais negativas, com previsões de elevados déficits.

E agora se considera "razoável" a "diminuiçãa" da dimensão desses montantes, fixando-se metas negativas "menos negativas" do que as anteriores, sendo esse o "avanço" conquistado.

Nos próximos dias será apresentado o projeto de lei de diretrizes orçamentárias federal para 2019, com a definição da nova meta fiscal e veremos o que se pretende fazer. Uma definição de substancial importância, pois define a dimensão que se dará ao pagamento do serviço da dívida, o que impacta diretamente no quanto haverá de recursos para as demais despesas, entre as quais estão os gastos com as diversas políticas públicas. ${ }^{7}$

3 “Após 14 meses, Temer desiste da Previdência". O Estado de S. Paulo, 19 de fevereiro de 2018.

4 Item 5 das prioridades elencadas - Nova lei de finanças públicas - PL 295, de 2016 ("Governo apresenta 15 propostas como prioritárias para a economia do Brasil”. Notícias do Planalto, 19 de fevereiro de 2018).

5 Nesta edição, p. 269-274.

6 "Falta de ajuste deteriora dívidas de União, estados e município". Folha de S.Paulo, 29 de março de 2018.

7 Decisôes financeiras fundamentais são tomadas na Lei de Diretrizes Orçamentárias, nesta edição, p. $155-160$. 
Boa parte do que está acontecendo decorre do desrespeito às normas e aos princípios de responsabilidade fiscal. No Rio de Janeiro, por exemplo, o caso mais grave, a forte recessão foi agravada pela queda no preço do petróleo e, consequentemente, na arrecadação dos royalties. Tendo boa parte da economia atrelada à cadeia de óleo e gás, como ressaltou Raul Veloso, seus problemas foram magnificados. ${ }^{8}$ Talvez essas consequências danosas não teriam ocorrido se tivesse sido observado que os royalties de petróleo têm natureza de receitas de capital, como bem destacado por Andressa Torquato Fernandes em obra recente, ${ }^{9}$ na qual mostra que os royalties não poderiam, por força do artigo 44 da LRF, ser usados em despesas correntes, apenas em despesas de capital, basicamente investimentos, propiciando com isso uma gestão responsável desses recursos no longo prazo. Aliás, sobre a sua aplicação em investimento, o município de Ilhabela tem dado um bom exemplo ao criar o primeiro Fundo Soberano Municipal do petróleo, visando garantir a disponibilidade dessa receita pública no futuro. ${ }^{10}$

Constata-se o pouco apreço por medidas estruturais mais relevantes, que vão efetivamente produzir os resultados almejados, como as que estabelecem as definições e rumos a seguir, com um planejamento que conduza as atividades de forma coerente e previsível. Em vez disso, o que ocupa a agenda são medidas emergenciais, na tentativa de interpretar a legislação de modo a conseguir soluçóes que importam em evitar o descumprimento frontal e claro da legislação, mas sem alterar as causas do problema.

É o caso da "regra de ouro", que, em face das dificuldades financeiras crescentes e cada vez mais intensas, impõe limites cuja ultrapassagem fica cada vez mais iminente. Buscam-se alternativas como a desvinculação da destinação dos recursos do Fundo de Fiscalização das Telecomunicações (Fistel) e dos royalties de petróleo. Ultrapassagem que, por sinal, já foi evitada com o ingresso de recursos decorrentes de devolução ao Tesouro de empréstimos tomados pelo BNDES. E que se pretende impedir contando-se com dezenas de bilhões de recursos oriundos dos "fundos Soberano e Nacional de Desenvolvimento e cancelamento de restos a pagar antigos (relativos a obras não iniciadas), além dessas desvinculaçôes novas anunciadas e medidas administrativas de gerenciamento de paga-

\footnotetext{
8 Notícia já citada, "Como tirar os estados do buraco".

9 Andressa G. Torquato Fernandes. Royalties do petróleo e orçamento público: uma nova teoria. São Paulo: Blucher, 2016. A versão eletrônica do livro está disponível gratuitamente no site da Editora Blucher <www.blucher.com.br $>$ pelo selo Open Access.

$10<$ http://iis.org.br/farol-da-ilha/fundo-e-conselho-dos-royalties/>.
} 
mentos", conforme anunciado pela Secretária do Tesouro Nacional, Ana Paula Vescovi. ${ }^{11}$

Ou seja, uma verdadeira "caça ao tesouro" de recursos escondidos nas gavetas da gigantesca máquina que é a administração pública federal, que, achados aqui e acolá, tentam postergar o que parece ser uma iminente "decretação de falência" e colapso das contas públicas.

Coloca-se em xeque o tempo todo a legislação financeira, em um verdadeiro "esticar de cordas" interpretativo, para atingir o limite - e eventualmente ultrapassar - da legalidade, colocando em sério risco a efetividade e credibilidade das normas de responsabilidade fiscal. Agravada pela necessidade de se observar o "teto de gastos" imposto pela Emenda Constitucional 95, de 2016. E tudo isso para produzir resultados que se sabe de antemão terão efeitos imediatos, de curto prazo, que em nada vão colaborar para a solução definitiva dos problemas enfrentados - a sempre presente emergência para a solução de problemas imediatos, verdadeiros "incêndios" que precisam ser apagados, que invariavelmente consomem toda a energia da máquina pública. Com isso, as medidas estruturais, que efetivamente podem vir a trazer soluções definitivas, deixam de receber qualquer atenção e nunca são implementadas.

A legislação financeira fica sendo o tempo todo colocada em risco, exigindo uma eterna vigilância para que a cultura da responsabilidade fiscal não se perca, pois a "sustentação da responsabilidade fiscal não se firma sobre a concreção jurídico-normativa da LRF, mas no compromisso sério e duradouro dos que governam o país com o equilíbrio das finanças públicas e o controle da inflação e do endividamento", como bem pontua Weder de Oliveira. ${ }^{12}$

Chamo a atenção para o fato de que houve substancial alteração nos rumos do governo com a queda da presidente Dilma e dos principais partidos que davam sustentação a seu mandato, com o presidente Michel Temer assumindo o comando da nação e claramente impondo outra direção na condução da máquina pública. Apesar disso, não se constata ter havido qualquer alteração significativa no Plano Plurianual (Lei 13.249, de 13 de janeiro de 2016 - PPA 2016-2019) vigente, principal documento que expressa formalmente e dá (ou deveria dar) sustentação jurídica e coesão às atividades da administração pública federal para o final do man-

11 "Tesouro quer recursos de royalties para 'regra de ouro'". Valor Econômico, 28 de março de 2018. Ver também a notícia "Governo quer ligar despesas a créditos orçamentários para cumprir Regra de Ouro”, in EBC - Agência Brasil, 27 de março de 2018.

1215 anos de Lei de Responsabilidade Fiscal: Um pouco de história e de essência. In: Responsabilidade Fiscal: análise da Lei Complementar 101/2000. OAB, 2015. 
dato que deve cumprir e o primeiro ano que sucede. O que permite concluir que: a) não houve alteração nos rumos do país, o que é bastante improvável; b) houve alteração, mas não fizeram constar do PPA, deixando de materializar referidas alteraçōes e lhes dar sustentação jurídica; ou c) deixou evidente que o PPA é um documento meramente formal, que não tem qualquer efetividade - hipótese que se afigura como a mais provável.

Ao fazer isso, vê-se que as graves falhas estruturais, tanto econômicas como jurídicas, continuam presentes, não se consegue abandonar a "administração-bombeiro", e o que se tem é um país sem rumo e fadado a repetir, intensificar e agravar os mesmos problemas de sempre, deixando poucas esperanças que possa melhorar.

Impor um planejamento que dê credibilidade e segurança jurídica aos atores governamentais, sociais e econômicos, fundamentais para um desenvolvimento sustentável torna-se uma possibilidade cada vez mais distante. Agir com os olhos voltados para trás, dirigindo uma nação com o que se vê pelo retrovisor, e não pelo para-brisa, não pode dar bom resultado. $O$ pão continuará faltando, e vamos continuar brigando sem que ninguém tenha razão. 
